\title{
Estimation Method of the Consolidation Potential of Rural Residential Land considering Farmers' Willingness
}

\author{
Bo Liu $\mathbb{D}^{1},{ }^{1}$ Chen Chen, ${ }^{1}$ Liang Tang $\left(\mathbb{D},{ }^{2}\right.$ Zhisong Chen $\mathbb{D D}^{3}$ and Cheng Cao ${ }^{4}$ \\ ${ }^{1}$ Ginling College, Nanjing Normal University, Nanjing, China \\ ${ }^{2}$ Business School, Fuyang Normal University, Fuyang, China \\ ${ }^{3}$ Business School, Nanjing Normal University, Nanjing, China \\ ${ }^{4}$ College of Land Management, Nanjing Agricultural University, Nanjing, China \\ Correspondence should be addressed to Liang Tang; tangliang99@sohu.com
}

Received 2 November 2021; Accepted 15 December 2021; Published 31 December 2021

Academic Editor: Sundarapandian Vaidyanathan

Copyright ( $\odot 2021$ Bo Liu et al. This is an open access article distributed under the Creative Commons Attribution License, which permits unrestricted use, distribution, and reproduction in any medium, provided the original work is properly cited.

\begin{abstract}
The work of rural residential land consolidation is related to several aspects, such as optimization of the structure of rural layout and improvement of the ecological environment in rural areas. Therefore, the work of rural residential land consolidation must be carried out rationally and effectively on the basis of scientific estimation of the real potential of rural residential land consolidation. However, according to the existing estimation method of the consolidation potential of rural residential land, it ignores the willingness of farmers who are closely related to it and cannot meet the current requirements of rural residential consolidation. Under the background of rural revitalization and based on the new requirements of standardizing rural land improvement work, this study organically combines rural residential land consolidation and the protection of farmers' land rights and interest from the perspective of farmers' wishes. The research uses a multimethod integrated approach (the per-capita construction land standard method, per-household construction land standard method, and town system planning method) to measure theoretical potential of the rural residential land consolidation and constructs a correction index system in two dimensions: natural conditions and economic feasibility. And then, this study further optimizes the correction index system from the perspective of farmers' willingness. Finally, the feasibility of the estimation method is verified by a case. The research will initiate new ideas for estimating land consolidation potential in residential areas and provide references for the work and the special plan of rural residential land consolidation in various localities.
\end{abstract}

\section{Introduction}

As the general background of the urbanization process continues to accelerate, the trend of the one-way flow of rural production factors (e.g., population and land) to cities also has accelerated significantly. As such, a new reality has emerged: the size of the rural population has continued to decrease, and the size of towns has continued to increase. This has created, to a certain extent, a situation of land constraint for urban construction. In contrast, the originally tight rural residential land has begun to be utilized inefficiently and even has been left idle in large quantities. The obvious shortage of rural labor has increased both the pressure of arable land protection and the cost of agricultural production. For issues relating to agriculture, rural areas and farmers, especially in agriculture and rural development, are under great pressure.

The timely implementation of rural residential land consolidation not only can attract urban capital into rural areas but also can revitalize rural construction land. In addition, the development of rural residential land consolidation can adjust the structure of urban and rural construction land and alleviate land conflicts through spatial exchange, which is an effective means to improve the landuse intensification of rural settlements and provide a land index for urban development [1].

As an important tool for building new countryside and coordinating urban and rural development, rural residential 
land consolidation is not only an effective means to realize the balance of arable land, increase the utilization rate of rural land, and improve the rural environment but also an important basis for implementing the rural revitalization strategy [2]. Considering the current rural development situation and the pressure on urban land, rural settlements have been developed vigorously in various regions. This not only improves the living environment in rural areas but also provides the required construction land index for urban development, a certain amount of development funds, and high-quality arable land for rural development in the context of the policy of linking urban and rural construction land increases and decreases. As a result, the development of rural residential land consolidation has become a major spatial strategy in the field of land management to realize the coordination of resource protection and guarantee development.

As rural residential land consolidation is the improvement of land-use intensification through certain measures, the degree of improvement of the level of land-use intensification for a rural settlement is related to factors such as the current status of land use in the rural settlement and the measures used. This means that the potential of rural residential land consolidation is different for different settlements. The rural residential land consolidation potential includes the area of agricultural, construction, and commercial lands that can be increased through engineering, planning, technical, and administrative means based on detailed surveys.

According to the principle of operability, the potential of rural residential land consolidation can be divided into theoretical and realistic potential. Theoretical potential refers to the theoretical land area that can be increased through rural residential land consolidation work provided that all conditions are met and all stakeholders cooperate in accordance with the relevant policies. The theoretically calculated potential of rural residential land consolidation is not fully realized in real life because various factors constrain rural residential land consolidation work. Therefore, the actual area of land that can be increased by natural settlement consolidation work, which is obtained based on the practical analysis of the operability of the theoretical potential, is called the realistic potential. In the practical operation of rural residential land consolidation, the main influencing factors include nature, policy, economy, technology, and farmers' willingness. Therefore, the realistic potential of rural residential land consolidation reflects the natural adaptability, policy compliance, economic rationality, technical feasibility, and farmers' aspirations of rural residential land consolidation. On this basis, it is necessary to correct the natural, policy, economic, and farmer aspirations regarding rural residential land consolidation potential. Thus, the actual potential of rural residential land consolidation, that is, the realistic potential, is calculated.

The work of rural residential land consolidation is scientific and serious and is related to the optimization of rural layout structure, the improvement of ecological environment in rural areas, and many other aspects. Therefore, it is necessary to carry out the work rationally and effectively on the basis of scientific estimation of the real potential of rural residential land consolidation. This work involves the vital interests of farmers, so it is necessary to combine rural residential land consolidation and the protection of farmers' land rights on the basis of extensive consultation with farmers' willingness to avoid a series of negative social impacts caused by the "merging of villages into one house" in places such as Shandong. In the Rural Revitalization Plan (2018-2022), issued by the Central Committee of the Communist Party of China and the State Council, "the relocation of rural settlements and the removal of villages must respect farmers' willingness and be agreed by the villagers meeting. Farmers' willingness must be respected and approved by the villagers' meeting". In addition, "No forced relocation or concentration of farmers' buildings" is explicitly stated. Therefore, it is important to conduct scientific research on the method of measuring the consolidation potential of rural settlements based on the survey of farmers' willingness.

1.1. Literature Review. In response to the problem of rural residential land consolidation, significant exploration has been done in regard to rural settlement management (e.g., layout influencing factors and rural settlement zoning) in China and abroad. Rural settlements are the spatial carriers of rural development and represent a widespread and important type of land use in rural areas. Since its creation in a specific natural and human environment, rural settlements have been in a state of gentle evolution influenced by the natural increase and decrease of the rural population and the slow growth of the rural economy [3]. Studies on rural settlements have focused on changes in the number of rural settlements [4], spatial distribution [5, 6], utilization status [7], and remediation methods [8,9]. On this basis, the exploration of the role of the influence of geographical conditions, institutional reform, population mobility, industrial and economic development, and the construction of public services on the evolution of rural settlements $[10,11]$ can reveal the mechanism of change in the morphology of rural settlements to a certain extent. Some studies on the transformation of rural settlements have focused on the scale increment of land use, structural transformation, functional transformation, and spatial differentiation characteristics and have achieved landmark results [12-14].

The evaluation of the layout of rural settlements and the analysis of their influencing factors are conducted mainly in terms of natural endowments, production and living conditions, and economic and social conditions [15]. Studies have shown that the influence of agriculture on settlements is gradually weakening [16]. The development of rural settlements is influenced by history and culture, natural geographical conditions, the socioeconomic development level, and customs and practices [17]. Some scholars have selected typical cases for the study of rural residential land consolidation. They have explored the classification of rural settlement types, landscape characteristics, and driving factors. For example, Long et al. focused their research on the development of agriculture-dominated villages, 
especially on the issues of village reconstruction and hollow villages [18]. Xi et al. analyzed the process of spatial morphology evolution of tourism-dominated villages over the past 30 years, taking Yesanpo as an example [19]. By quantitatively portraying the spatial and temporal changes in the expansion process of rural settlement sites, these past studies have revealed the characteristics of rural settlement sites. Dong et al. analyzed the variability of the drivers of the spatiotemporal evolution of different types of settlements [20]. Zhang Ruijuan et al. proposed an optimal regulation strategy based on the classification of the types of rural settlements, taking into account the actual situation [21]. Based on the combined characteristics of the scale, morphology, and distribution of rural settlements, Dong Guanglong et al. classified the types of rural settlements in the Yellow Huaihai Plain. Comparatively, they analyzed the spatial morphology and evolutionary characteristics of different types of rural settlements [22].

Rural residential land consolidation potential estimation is not only an important part of land remediation but also a core part of land remediation planning [23]. The scientific estimation of rural residential land consolidation potential provides an important basis for determining the scale of consolidation, selecting the consolidation mode, and screening the consolidation effect [24]. Owing to the difference in the human-land relationship, only a small part of foreign research is dedicated to the potential of rural residential land consolidation. In contrast, domestic research in this area has already started and has produced some research results. Rural residential land consolidation potential estimation studies involve contents, such as the connotation of potential, evaluation index system, and estimation methods [25]. Commonly used estimation methods are derived mainly from the potential theoretical perspective to directly measure the potential of the consolidation area. They deviate greatly from the actual released realistic potential. Accordingly, scholars later built a series of models with correction coefficients. These scholars chose correction indicators from natural, economic [26], social acceptability [27], and implementation subjects [28] to correct the theoretical potential and thus derive the realistic potential.

Today, more research results are available on the management of rural settlements in China and abroad. In particular, many research methods have been developed to measure rural residential land consolidation potential, and they have been widely applied in practice. Based on the existing studies, however, there are two problems with the current research: (1) The research does not consider the farmers' willingness to finish rural settlement. Because rural residential land consolidation involves the vital interests of rural residents, if the farmers' opinions are not fully considered and their interests are harmed, a series of social incidents may occur. Accordingly, it is necessary to take into account farmers' willingness in rural residential land consolidation to cope with the potential of rural residential land consolidation in advance. (2) The research does not combine rural residential land consolidation with territorial consolidation. However, rural residential land consolidation is a hot issue in the current urban management. In the process of territorial consolidation, the issue of rural residential land consolidation inevitably will be involved. Therefore, it needs to be considered in an integrated manner. In view of the shortcomings in previous research studies, this paper proposes a methodological system for measuring the potential of rural residential land consolidation based on the consideration of farmers' willingness, which has a certain research value.

\section{Method}

2.1. Rural Residential Land Consolidation Potential Estimation Framework System considering Farmers' Willingness. The theoretical potential is the basis of rural residential land consolidation potential estimation. Realistic potential is a modification of the theoretical potential, which is based on the influencing factors that exist in an actual work to reflect the actual consolidation potential of a settlement in a more realistic way. Therefore, the specific steps needed to carry out the rural residential land consolidation potential estimation are as follows.

2.1.1. Calculation Analysis of the Theoretical Potential. The main methods for calculating the theoretical potential of rural residential land consolidation are the standard method of per-capita construction land, the standard method of perhousehold construction land, and the method of town system planning. In this study, a combination of the three methods is attempted; that is, the theoretical potential of rural residential land consolidation is calculated using each of the three methods. Accordingly, certain weights are assigned to each method to obtain the combined value of the theoretical potential of rural residential land consolidation.

\subsubsection{Calculation of Realistic Potential considering Natural Conditions and Economic Feasibility. Various factors, such as the natural environment and economic conditions, can have an impact on the estimation of the realistic potential of rural residential land consolidation. Given that natural conditions and economic feasibility are reflected in several aspects, this study first constructs feedback indicators of natural conditions and economic feasibility, corrects the theoretical potential based on the weights and scores of each indicator in the feedback indicators, and then calculates the correction coefficients. On this basis, it is necessary to calculate a realistic potential considering natural conditions and economic feasibility.}

\subsubsection{Calculation of Collation Reality Potential considering} Farmers' Willingness. Farmers' willingness to organize their settlements has an impact on their real potential. Therefore, it is necessary to correct the realistic potential based on the survey of farmers' willingness. According to an in-depth investigation and analysis of the mechanism of the impact of rural residential land consolidation on farmers, it is necessary to construct an index system of the impact of rural residential land consolidation on farmers and calculate the 
correction coefficient of realistic potential considering farmers' willingness. On this basis, it is also necessary to calculate the realistic potential considering farmers' willingness.

2.1.4. The End Result of the Realistic Potential of Rural Residential Land Consolidation. The integration needs to consider the realistic potential based on natural conditions, economic feasibility, and the realistic potential considering farmers' willingness to calculate the final realistic potential.

\subsection{A Multimethod Integrated Approach for Measuring the} Theoretical Potential of Rural Residential Land Consolidation. On the basis of in-depth rural residential land consolidation survey and analysis, the per-capita construction land standard method, per-household construction land standard method, and town system planning method were chosen as theoretical potential calculation methods.

Assume that the theoretical potential of rural residential land consolidation is calculated by the per-capita construction land standard method, per-household construction land standard method, and town system planning method, which are $q_{1}, q_{2}$, and $q_{3}$, respectively. Moreover, the weights of the three methods are $w_{1}, w_{2}$, and $w_{3}$, respectively. Then, the theoretical potential of rural residential land, $q$, is

$$
q=w_{1} g q_{1}+w_{2} g q_{2}+w_{3} g q_{3}
$$

Here, $q$ is the theoretical potential of rural residential land consolidation; $q_{1}, q_{2}$, and $q_{3}$ are the theoretical potential calculated by using the per-capita construction land standard method, per-household construction land standard method, and town system planning method, respectively; and $w_{1}, w_{2}$, and $w_{3}$ are the weight of the per-capita construction land standard method, per-household construction land standard method, and town system planning method, respectively.

We used the Group-Decision Analytic Hierarchy Process (GAHP) to determine the weights of these three methods. In other words, the relative importance weights of the three methods are determined by several experts according to the steps and requirements of the hierarchical analysis method, and the arithmetic mean of the results of each expert's determination is taken as the final weight. Given the relative maturity of the method, it is not repeated in this paper.

\subsection{Calculation of the Realistic Potential of Rural Residential} Land Consolidation Based on Natural Conditions and Economic Feasibility. The theoretical potential of rural residential land consolidation cannot be fully realized, and the actual realistic potential needs to be obtained on the basis of an analysis of operability. Many factors affect the realistic potential. Therefore, in this section, we first measure the correction coefficient $C_{N-E}$ of the realistic potential of rural residential land consolidation in two dimensions: natural conditions and economic feasibility.
2.3.1. Evaluation Index System. This study constructs a realistic potential correction coefficient evaluation index system considering natural conditions and economic feasibility. The details are given in Table 1.

Natural conditions indicate the degree of limitation of natural conditions in the area for rural residential land consolidation. In this study, three indicators are selected to measure natural conditions, namely, the aggregation of rural settlements $\left(B_{11}\right)$, the average slope of rural settlements $\left(B_{12}\right)$, and the topographic relief $\left(B_{13}\right)$. The greater the aggregation of rural settlements, the greater the number of people gathered in the area, the more difficult it is to organize, and the easier it is for the area to develop into an agglomeration. The larger the average slope of rural settlements and the greater the topographic relief, the less conducive the topographic structure of the area is to carrying out the consolidation work and the consolidation may face a certain level of pressure.

Economic feasibility is an indicator that characterizes the size of the local government's investment capacity. In this study, three indicators, per-capita gross domestic product (GDP) $\left(B_{21}\right)$, available fiscal revenue $\left(B_{22}\right)$, and percentage of primary industry revenue $\left(\mathrm{B}_{23}\right)$, are selected as indicators of economic feasibility. The higher the per-capita GDP, available fiscal revenue, and percentage of primary industry revenue, the greater the assurance of funding that local governments can devote to rural residential land consolidation.

2.3.2. Determination of the Evaluation Index System Weight. The weights are determined using the GAHP for the same method. In this case, the weight values of each indicator are characterized in the following way:

(1) The aggregation of rural settlements $\left(B_{11}\right), Q_{N-E}$

(2) The average slope of rural settlements $\left(\mathrm{B}_{12}\right), w_{B 12}$

(3) The topographic relief $\left(\mathrm{B}_{13}\right), w_{B 13}$

(4) Per-capita GDP $\left(\mathrm{B}_{21}\right), w_{B 21}$

(5) Available fiscal revenue $\left(\mathrm{B}_{22}\right), w_{B 22}$

(6) Percentage of primary industry revenue $\left(\mathrm{B}_{23}\right), w_{B 23}$

2.3.3. Standardization of Indicator Values. Assuming that the original value of each indicator in the realistic potential correction coefficient evaluation index system is $x_{B_{i j}}$, then for the six indicators in the index system, each data set is standardized by the extreme difference.

For convenience, the standardized index values are noted as. $X_{B_{i j}}$. The formula for processing positive indicators is

$$
X_{B_{i j}}=\frac{x_{B_{i j}}-\min \left(x_{B_{i j}}\right)}{\max \left(x_{B_{i j}}\right)-\min \left(x_{B_{i j}}\right)} .
$$


TABLE 1: Rural residential land consolidation real potential correction factor evaluation index system considering natural conditions and economic feasibility.

\begin{tabular}{lcc}
\hline Guideline layer & Indicator layer & Nature of indicator (forward/reverse) \\
\hline & The aggregation of rural settlements $\mathrm{B}_{11}$ (dimensionless) & - \\
Natural conditions $\mathrm{B}_{1}$ & The average slope of rural settlements $\mathrm{B}_{12}(\%)$ & - \\
& The topographic relief $\mathrm{B}_{13}(\%)$ & + \\
& Per-capita GDP $\mathrm{B}_{21}(\mathrm{RMB})$ & + \\
Economic feasibility $\mathrm{B}_{2}$ & Available fiscal revenue $\mathrm{B}_{22}(\mathrm{RMB} 10,000)$ & + \\
& Percentage of primary industry revenue $\mathrm{B}_{23}(\%)$ & + \\
\hline
\end{tabular}

$$
X_{B_{i j}}=\frac{\max \left(x_{B_{i j}}\right)-x_{B_{i j}}}{\max \left(x_{B_{i j}}\right)-\min \left(x_{B_{i j}}\right)} .
$$

Here, $X_{B_{i j}}$ denote the index values after standardization; $x_{B_{i j}}$ is the original value of index;max $\left(x_{B_{i j}}\right)$ is the maximum value of the index; and $\min \left(x_{B_{i j}}\right)$ is the minimum value of the index.

2.3.4. Correction Factor. The real potential correction factor of rural residential land consolidation considering natural conditions economic feasibility is $\eta_{N-E}$; then,

$$
\eta_{N-E}=\sum_{i=1}^{n}\left(X_{B_{i j}} \times w_{B_{i j}}\right) \text {. }
$$

Here $\eta_{N-E}$ is the rural residential land consolidation real potential correction factor considering natural conditions economic feasibility; $X_{B_{i j}}$ is the index value after standardized treatment; and $w_{B_{i j}}$ is the index weight.

\subsubsection{Realistic Potential of Rural Residential Land Consoli-} dation Based on Natural Conditions and Economic Feasibility. Specifying the realistic potential of rural residential land consolidation based on natural conditions and economic feasibility as $Q_{N-E}$, then

$$
\mathrm{Q}_{N-E}=q \times \eta_{N-E} .
$$

We have the following:

(1) $Q_{N-E}$ : the realistic potential of rural residential land consolidation based on natural conditions economic feasibility

(2) $\eta_{N-E}$ : considering natural conditions, the realistic potential correction factor of economic feasibility

(3) $q$ : theoretical potential

\subsection{Real Potential Calculation of Rural Residential Land} Consolidation Based on Farmers' Willingness. As for actual users of rural settlements, farmers have lived in rural settlements for a long time and are dependent on them for their livelihood and psychological well-being. Because of this, the willingness of farmers to carry out settlement preparation work, i.e., the willingness of farmers to settle settlement preparation, affects the actual potential of settlement preparation to a certain extent. Therefore, farmers' willingness should be taken into account when carrying out the calculation of consolidation potential. And, farmers' willingness is reflected in several aspects. In such a context, it is required to propose a comprehensive and systematic index system of the impact of rural settlement on farmers based on the specific analysis of the mechanism of the impact of rural residential land consolidation on farmers and to clarify farmers' willingness size through the design and distribution of questionnaires.

On this basis, a realistic potential considering farmers' willingness needs to be calculated.

The real potential of rural residential land consolidation considering farmers' willingness is $Q_{Y}$; then,

$$
Q_{Y}=q \times \eta_{Y} .
$$

We have the following:

(1) $Q_{Y}$ : the real potential of consolidation considering farmers' willingness

(2) $\eta_{Y}$ : correction factor of realistic collation potential considering farmers' willingness

(3) $q$ : collation of theoretical potential

In the framework of realistic potential calculation, the problem of calculating realistic potential considering farmers' willingness is a complex problem. Farmers' willingness is reflected and expressed in certain ways and eventually reflected in the satisfaction dimensions, so it is necessary to find out the real willingness of farmers through systematic survey work. Therefore, it is necessary to find out the real willingness of farmers through systematic survey work and use it to calculate the real potential. Based on this, the following is a detailed discussion of this issue.

2.4.1. Farmers' Willingness Survey Method in Rural Residential Land Consolidation Potential Estimation. In the previous paper, a rural residential land consolidation potential estimation framework system considering farmers' willingness is proposed to support the development of rural residential land consolidation potential estimation. In this system, a farmers' willingness survey is used to conduct rural residential land consolidation potential estimation. In this system, a farmers' willingness survey is the key to rural residential land consolidation potential estimation. Based on this, this section will investigate the method of farmers' willingness survey in rural settlements consolidation potential estimation. 
2.4.2. Structural Analysis of Farmers' Willingness in Rural Residential Land Consolidation Based on the Pressure-StateResponse Theory. For farmers, their willingness to work on rural residential land consolidation is reflected in two main ways: results and behavior. Therefore, when analyzing the structure of farmers' willingness in rural residential land consolidation, the analysis also should be constructed according to two dimensions: outcome and behavior. Moreover, farmers' willingness will be reflected and expressed in a certain way and finally reflected in the dimensions of satisfaction. This also means that the farmers' willingness structure in rural residential land consolidation can be reflected by the three dimensions of "pressure-stateresponse" (PSR), which is consistent with the basic idea of the PSR theory.

The analysis of farmers' willingness structure in rural residential land consolidation using PSR theory not only can reflect the cyclic coordination relationship of "actionfeedback-action" constituted by the three dimensions of pressure, state, and response faced by farmers in rural residential land consolidation but also can characterize the current situation of farmers in rural residential land consolidation and their judgment of future outcomes in a unified manner. Among them, government policies and farmers' conditions exert a certain amount of pressure on their willingness to express themselves in rural residential land consolidation. The farmers' willingness to change their living environment reflects the current level of living in rural settlements. The farmers' satisfaction with rural residential land consolidation reflects the results of this work to a certain extent. Among them, the two dimensions of pressure and state reflect the process of rural residential land consolidation, whereas the corresponding system reflects the result of rural residential land consolidation. On this basis, the structure of farmers' willingness in rural residential land consolidation is constructed according to three dimensions: government policy and farmers' own conditions (pressure dimension), the current settlement level of farmers (state dimension), and farmers' satisfaction with rural residential land consolidation (response dimension).

According to this analysis, the overall idea of constructing the structure of farmers' willingness in rural residential land consolidation based on PSR theory is shown in Figure 1.

According to the overall framework of farmers' willingness structure in the rural residential land consolidation potential estimation, shown in Figure 1, the specific contents of farmers' willingness structure are proposed, as shown in Table 2 .

Based on the structure of farmers' willingness in the potential estimation of rural residential land consolidation (Table 2), the constructed structure of farmers' willingness can reflect farmers' willingness toward rural residential land consolidation more comprehensively. The scientific and reasonable design of the research questionnaire and the implementation of the research work are conducive to the true reflection of the potential size of rural residential land consolidation.
2.4.3. Farmers' Willingness Questionnaire Design in Rural Residential Land Consolidation Potential Estimation. When surveying farmers' willingness to measure the rural residential land consolidation potential, the factors involved in the structure of farmers' willingness need to be problematized by answering questions that can reflect farmers' opinions on each factor quantify them.

To quantify and problematize the factors involved in the structure of farmers' willingness, this paper adopts a Likert scale to quantify the factors by means of a scale from 1 to 10 so that respondents can realize the purpose of the research according to their own understanding and grasp of the issues.

On this basis, the factors of the farmers' willingness structure of the rural residential land consolidation potential measure (Table 2) are problematized separately. After problematizing the factors of the farmers' willingness structure in measuring the potential of rural residential land consolidation, a questionnaire was designed according to the requirements of the Likert scale.

According to this analysis, a farmers' willingness questionnaire in rural residential land consolidation potential estimation was developed, as shown in Appendix 1.

2.4.4. Methodology for Implementing and Analyzing the Results of the Farmers' Willingness Survey in the Estimation of Rural Residential Land Consolidation Potential. In the process of measuring the potential of rural residential land consolidation, a farmers' willingness survey is the first issue to be addressed. The willingness of affected farmers can be surveyed by means of sampling to reflect the level of farmers' support for rural residential land consolidation work. In the sampling process, the sampling proportion should be no less than $10 \%$ of the number of local households included in the scope of rural residential land consolidation.

By distributing the questionnaires and collecting and collating them, after eliminating the unqualified questionnaires, the results of the survey of the questions corresponding to each factor can be taken as the arithmetic mean of the scores for each question in the questionnaire as the final score of each willingness factor.

To determine the weights of each factor of farmers' willingness, the same GAHP is used for determination.

Representation of the weight of each factor in the structure of farmers' willingness in the estimation of rural residential land consolidation potential in this paper is listed in Table 3.

The scores of each factor in Table 2 are $E_{m n}$ ( $\left.m=p, s, r ; n=p_{i}, s_{i}, r_{i}\right)$, the weights of each factor are $w_{m n}$, and the score of farmers' willingness in a region is $T$. Then,

$$
T=\sum E_{m n} \times w_{m n}
$$

According to equation (6),

$$
\eta_{Y}=\frac{T}{10}
$$

where $\eta_{Y}$ is farmers' willingness-based rural residential land consolidation actual potential correction factor. 


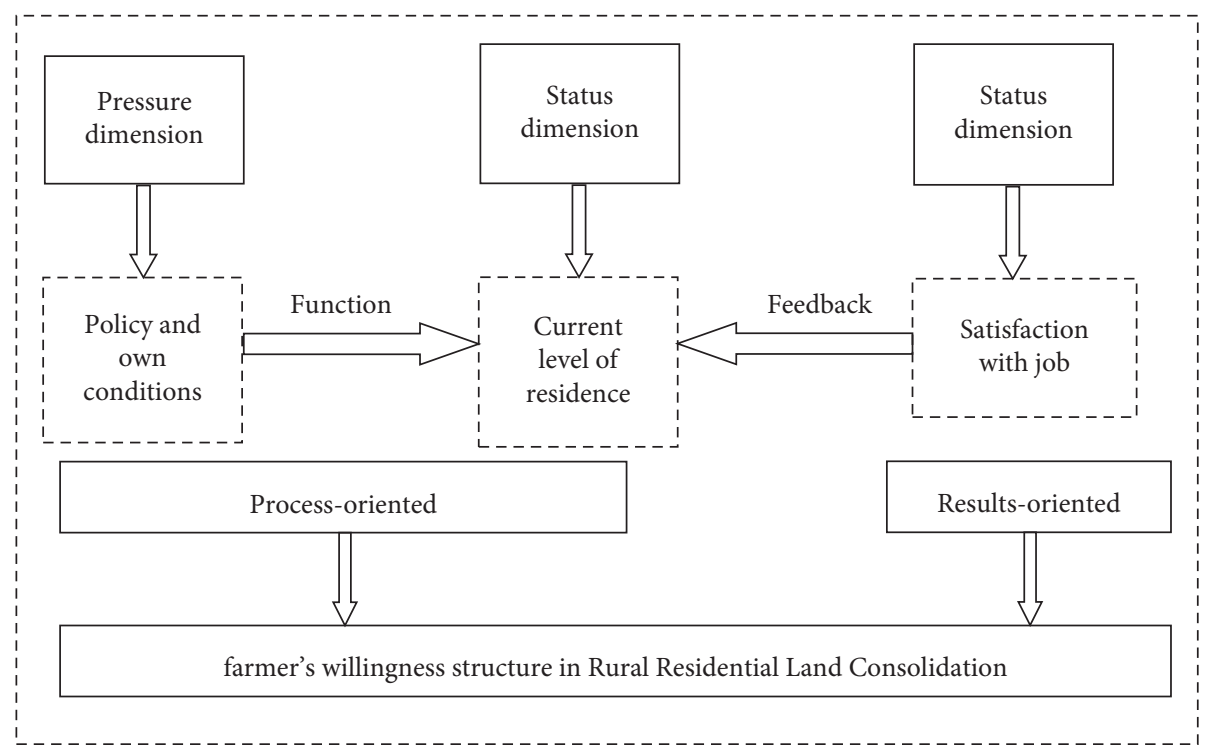

Figure 1: Schematic diagram of the overall framework for the construction of farmers' willingness structure in rural residential land consolidation based on PSR theory.

TABLE 2: Farmers' willingness structure in rural residential land consolidation potential estimation.

\begin{tabular}{|c|c|}
\hline Dimension & Specific representation \\
\hline Stress dimensions $\mathrm{P}$ & $\begin{array}{c}\text { Farmers' attitudes toward policies related to settlement consolidation } \mathrm{P}_{1} \\
\text { Farmers' perceptions of rural residential land consolidation work } \mathrm{P}_{2} \\
\text { Farmers' understanding of the contradiction between land supply and demand } \mathrm{P}_{3} \\
\text { Age structure } \mathrm{P}_{4} \\
\text { Long-term employment of family members outside the home } \mathrm{P}_{5} \\
\text { Education level } \mathrm{P}_{6} \\
\text { Satisfaction level of housing area status } \mathrm{S}_{1}\end{array}$ \\
\hline Status dimensions $\mathrm{S}$ & $\begin{array}{l}\text { Satisfaction level of housing area status } S_{1} \\
\text { Satisfaction level of the current state of the surrounding environment } S_{2} \\
\text { Satisfaction level of the current status of supporting facilities } S_{3}\end{array}$ \\
\hline Response dimensions $\mathrm{R}$ & $\begin{array}{c}\text { Satisfaction level of housing area after consolidation } R_{1} \\
\text { Satisfaction level of household income after consolidation } R_{2} \\
\text { Satisfaction level of housing subsidy } R_{3} \\
\text { Satisfaction level of living conditions after consolidation } R_{4} \\
\text { Satisfaction level of supporting facilities after consolidation } R_{5}\end{array}$ \\
\hline
\end{tabular}

TABLE 3: Representation of the weight of each factor in the structure of farmers' willingness in the estimation of rural residential land consolidation potential.

\begin{tabular}{|c|c|c|}
\hline Dimension & Specific representation & $\begin{array}{c}\text { Results of weight } \\
\text { determination }\end{array}$ \\
\hline \multirow{6}{*}{ Stress dimensions $\mathrm{P}$} & Farmers' attitudes toward policies related to settlement consolidation $\mathrm{P}_{1}$ & $w_{P 1}$ \\
\hline & Farmers' perceptions of rural residential land consolidation work $\mathrm{P}_{2}$ & $w_{P 2}$ \\
\hline & Farmers' understanding of the contradiction between land supply and demand $\mathrm{P}_{3}$ & $w_{P 3}$ \\
\hline & Age structure $\mathrm{P}_{4}$ & $w_{P 4}$ \\
\hline & Long-term employment of family members outside the home $\mathrm{P}_{5}$ & $w_{P 5}$ \\
\hline & Education level $\mathrm{P}_{6}$ & $w_{P 6}$ \\
\hline \multirow{3}{*}{ Status dimensions S } & Satisfaction level of housing area status $S_{1}$ & $w_{S 1}$ \\
\hline & Satisfaction level of the current state of the surrounding environment $S_{2}$ & $w_{S 2}$ \\
\hline & Satisfaction level of the current status of supporting facilities $S_{3}$ & $w_{S 3}$ \\
\hline \multirow{5}{*}{ Response dimensions $\mathrm{R}$} & Satisfaction level of housing area after consolidation $R_{1}$ & $w_{R 1}$ \\
\hline & Satisfaction level of household income after consolidation $R_{2}$ & $w_{R 2}$ \\
\hline & Satisfaction level of housing subsidy $R_{3}$ & $w_{R 3}$ \\
\hline & Satisfaction level of living conditions after consolidation $R_{4}$ & $w_{R 4}$ \\
\hline & Satisfaction level of supporting facilities after consolidation $R_{5}$ & $w_{R 5}$ \\
\hline
\end{tabular}


Accordingly, the rural residential land consolidation actual potential considering farmers' willingness is calculated as $Q_{Y}$.

Based on (8), the end result of the realistic potential of rural residential land consolidation can be calculated as $Q$.

\subsection{Final Result of the Realistic Potential of Rural Residential} Land Consolidation. According to this analysis, this work needs to consider a number of factors-that is, on the basis of the theoretical potential calculation, the impact of natural, economic, farmers' willingness, and other factors needs to be integrated so that the calculated results are true and effective and are more in line with the reality of the requirements.

The arithmetic mean of the two calculations is taken as the final result of the actual potential calculated in Sections 3.3 and 3.4 .

If we denote the result of the realistic potential of rural residential land consolidation as $Q$, then

$$
Q=\frac{1}{2}\left(Q_{N-E}+Q_{Y}\right) \text {, }
$$

where $Q$ is final result of actual potential; $Q_{Y}$ is actual potential considering farmers' willingness; and $Q_{N-E}$ is actual potential based on natural conditions and economic feasibility.

\section{Case Study}

3.1. Rugao City Profile and Land-Use Status. Rugao City is located in the south of Jiangsu Province, a county-level city adjacent to the Yangtze River and the Yellow River. It is an important part of the Yangtze River Delta and the Shanghai metropolitan area. The district has 20 towns, with a total area of $1576 \mathrm{~km}^{2}$. In 2020, the per-capita disposable income of all residents in Rugao District was RMB 37,646, an increase of $6.1 \%$ from the prior year. Urban residents' per-capita disposable income was RMB 49,118, an increase of $4.6 \%$ from the prior year. The per-capita disposable income of rural residents was RMB 23,599, an increase of $7.7 \%$ from the prior year. The urban-rural income ratio shrank from $2.14: 1$ in 2019 to $2.08: 1$, and the balance of urban-rural integration development was remarkable.

In 2018, the agricultural land in Rugao was $104,445.15 \mathrm{ha}^{2}$, accounting for $66.26 \%$ of the total land area. The construction land was $39,090.12 \mathrm{ha}^{2}$, accounting for $24.80 \%$ of the total land area. Other lands occupied $14,097.97 \mathrm{ha}^{2}$, accounting for $8.94 \%$ of the total land area. As of 2018 , the total construction land in the city and county is $35,218.89 \mathrm{ha}^{2}$, accounting for $22.34 \%$ of the total area of the city, of which rural construction land accounts for $89.72 \%$ of urban and rural construction land.

In the current situation, a prominent feature of the current land use in Rugao is the high degree of land use. The utilization rate has exceeded $90 \%$. The proportion of rural construction land is too large, the land-use structure has large regional differences, and the degree of coordination needs to be improved. In the face of environmental and climate change, the ecological pressure on land use in Rugao
TABLE 4: Results of determining the weights of the three methods.

\begin{tabular}{lc}
\hline Method & Weight \\
\hline Per-capita construction land standard method & 0.314 \\
Per-household construction land standard method & 0.352 \\
Town system planning method & 0.334 \\
\hline
\end{tabular}

TABLE 5: Calculation results of the theoretical potential of 20 towns in Rugao City.

\begin{tabular}{lcc}
\hline Serial no. & Town name & Theoretical consolidation potential $q$ \\
\hline 1 & XZ1 & 2435.75 \\
2 & XZ2 & 2213.45 \\
3 & XZ3 & 1323.89 \\
4 & XZ4 & 1876.34 \\
5 & XZ5 & 1984.23 \\
6 & XZ6 & 2109.35 \\
7 & XZ7 & 2387.52 \\
8 & XZ8 & 2783.13 \\
9 & XZ9 & 893.56 \\
10 & XZ10 & 1204.82 \\
11 & XZ11 & 879.24 \\
12 & XZ12 & 2104.45 \\
13 & XZ13 & 1452.52 \\
14 & XZ14 & 1342.59 \\
15 & XZ15 & 873.14 \\
16 & XZ16 & 874.22 \\
17 & XZ17 & 689.73 \\
18 & XZ18 & 1342.16 \\
19 & XZ19 & 1235.19 \\
20 & XZ20 & 984.23 \\
\hline
\end{tabular}

is gradually increasing and the land-use intensification still has certain shortcomings. Moreover, according to the relevant planning data, the scale of new urban and rural construction land in Rugao in the future will be small. Thus, it is necessary for Rugao's municipal government to promote rural residential land consolidation work over time. Failing to do so will affect the sustainable development of the economy and society to a large extent.

3.2. Data Source. The data used for this study and its sources are as follows:

(1) Socioeconomic development data: from Rugao City Statistical Yearbook 2015-2020, based on the data of the previous Statistical Yearbook, which forecasts the relevant socioeconomic development data in 2025

(2) Current land-use data: from the 2018 Rugao City Land Use Change Database

(3) Planning data: from the General Land Use Plan (2006-2020) of the city and each town provided by the Rugao Natural Resources and Planning Bureau

(4) Other information: "Rugao City National Economic and Social Development 14th Five-Year Plan, 2035 Visionary Goals Planning Outline," and other documents 
TABLE 6: Determination of rural residential land consolidation actual potential correction factor evaluation index system weights considering natural conditions and economic feasibility.

\begin{tabular}{lccc}
\hline Guideline layer & Indicator layer & Nature of indicator (forward/reverse) & Indicator weights \\
\hline & The aggregation of rural & - & 0.243 \\
Natural conditions $B_{1}$ & settlements $B_{11}$ (dimensionless) & - & 0.112 \\
& The average slope of rural settlements $B_{12}(\%)$ & - & 0.105 \\
& The topographic relief $B_{13}(\%)$ & + & 0.137 \\
Economic feasibility $B_{2}$ & Per-capita GDP B $\mathrm{B}_{21}(\mathrm{RMB})$ & + & 0.179 \\
& Available fiscal revenue $\mathrm{B}_{22}(\mathrm{RMB} 10,000)$ & + & 0.224 \\
\hline
\end{tabular}

TABLE 7: Calculation of the realistic potential of rural residential land consolidation based on natural conditions and economic feasibility results for the 20 towns in Rugao.

\begin{tabular}{|c|c|c|c|c|}
\hline Serial no. & Town name & Theoretical consolidation potential $q$ & Correction factor $\eta_{N-E}$ & Actual potential $Q_{N-E}$ \\
\hline 1 & $\mathrm{XZ1}$ & 2435.75 & 0.58 & 1412.74 \\
\hline 2 & $\mathrm{XZ2}$ & 2213.45 & 0.67 & 1483.01 \\
\hline 3 & $\mathrm{XZ3}$ & 1323.89 & 0.68 & 900.25 \\
\hline 4 & $\mathrm{XZ4}$ & 1876.34 & 0.73 & 1369.73 \\
\hline 5 & XZ5 & 1984.23 & 0.48 & 952.43 \\
\hline 6 & XZ6 & 2109.35 & 0.53 & 1117.96 \\
\hline 7 & XZ7 & 2387.52 & 0.48 & 1146.01 \\
\hline 8 & $\mathrm{XZ8}$ & 2783.13 & 0.54 & 1502.89 \\
\hline 9 & XZ9 & 893.56 & 0.55 & 491.46 \\
\hline 10 & $\mathrm{XZ10}$ & 1204.82 & 0.63 & 759.04 \\
\hline 11 & XZ11 & 879.24 & 0.76 & 668.22 \\
\hline 12 & $\mathrm{XZ12}$ & 2104.45 & 0.77 & 1620.43 \\
\hline 13 & XZ13 & 1452.52 & 0.51 & 740.79 \\
\hline 14 & $\mathrm{XZ14}$ & 1342.59 & 0.62 & 832.41 \\
\hline 15 & XZ15 & 873.14 & 0.45 & 392.91 \\
\hline 16 & XZ16 & 874.22 & 0.58 & 507.05 \\
\hline 17 & XZ17 & 689.73 & 0.81 & 558.68 \\
\hline 18 & XZ18 & 1342.16 & 0.73 & 979.78 \\
\hline 19 & XZ19 & 1235.19 & 0.67 & 827.58 \\
\hline 20 & XZ20 & 984.23 & 0.77 & 757.86 \\
\hline
\end{tabular}

\subsubsection{Theoretical Potential Estimation of Rural Residential} Land Consolidation in Rugao City Based on the Multimethod Synthesis. We selected the three methods of the per-capita construction land standard method, the per-household construction land standard method, and the town system planning method to calculate the theoretical potential of rural residential land consolidation in Rugao City.

To determine the weights of the per-capita construction land standard method, per-household construction land standard method, and town system planning method, nine experts from Rugao City were gathered to determine the relative importance of the three methods. The relative importance weights of the three methods were determined according to the steps and requirements of the hierarchical analysis method. The arithmetic average of the results of the experts' judgment was taken as the final weight.

Table 4 lists the results of determining the weights of the three methods when measuring the theoretical potential of rural residential land consolidation in Rugao City.

The results of calculating the theoretical potential of 20 towns in Rugao City are given in Table 5.
3.3. Correction of Rural Residential Land Consolidation Potential in Rugao City Based on Natural Conditions and Economic Feasibility. We performed the rural residential land consolidation actual potential correction according to two dimensions: natural conditions and economic feasibility.

First, the weights of the rural residential land consolidation actual potential correction factor evaluation index system considering natural conditions and economic feasibility were determined according to the steps of GAHP. The results are given in Table 6 .

On this basis, combining the specific data of 20 towns in Rugao City and the normalization process, formula (4) was applied to calculate the rural residential land consolidation actual potential correction factor, $\eta_{N-E}$, considering natural conditions and economic feasibility. Based on the missing correction factor $Q_{N-E}$, the rural residential land consolidation actual potential based on natural conditions and economic feasibility was calculated according to (5). The calculation results are given in Table 7. 
TABLE 8: Results of determining the weights of the factors in the structure of farmers' willingness in the estimation of rural residential land consolidation potential.

\begin{tabular}{|c|c|c|}
\hline Dimension & Specific representation & $\begin{array}{c}\text { Results of weight } \\
\text { determination }\end{array}$ \\
\hline \multirow{6}{*}{ Stress dimensions $\mathrm{P}$} & Farmers' attitudes toward policies related to settlement consolidation $\mathrm{P}_{1}$ & 0.083 \\
\hline & Farmers' perceptions of rural residential land consolidation work $\mathrm{P}_{2}$ & 0.057 \\
\hline & Farmers' understanding of the contradiction between land supply and demand $\mathrm{P}_{3}$ & 0.089 \\
\hline & Age structure $\mathrm{P}_{4}$ & 0.104 \\
\hline & Long-term employment of family members outside the home $\mathrm{P}_{5}$ & 0.045 \\
\hline & Education level $\mathrm{P}_{6}$ & 0.059 \\
\hline \multirow{3}{*}{ Status dimensions $S$} & Satisfaction level of housing area status $S_{1}$ & 0.112 \\
\hline & Satisfaction level of the current state of the surrounding environment $S_{2}$ & 0.072 \\
\hline & Satisfaction level of the current status of supporting facilities $S_{3}$ & 0.042 \\
\hline \multirow{5}{*}{ Response dimensions $\mathrm{R}$} & Satisfaction level of housing area after consolidation $R_{1}$ & 0.045 \\
\hline & Satisfaction level of household income after consolidation $R_{2}$ & 0.068 \\
\hline & Satisfaction level of housing subsidy $R_{3}$ & 0.093 \\
\hline & Satisfaction level of living conditions after consolidation $R_{4}$ & 0.052 \\
\hline & Satisfaction level of supporting facilities after consolidation $R_{5}$ & 0.079 \\
\hline
\end{tabular}

TABLE 9: Calculation results of rural residential land consolidation actual potential considering farmers' willingness in 20 towns of Rugao City.

\begin{tabular}{|c|c|c|c|c|}
\hline Serial no. & Town name & Theoretical consolidation potential $q$ & Correction factor $\eta_{Y}$ & Actual potential $Q_{Y}$ \\
\hline 1 & $\mathrm{XZ1}$ & 2435.75 & 0.62 & 1510.17 \\
\hline 2 & XZ2 & 2213.45 & 0.54 & 1195.26 \\
\hline 3 & XZ3 & 1323.89 & 0.51 & 675.18 \\
\hline 4 & $\mathrm{XZ4}$ & 1876.34 & 0.38 & 713.01 \\
\hline 5 & XZ5 & 1984.23 & 0.73 & 1448.49 \\
\hline 6 & XZ6 & 2109.35 & 0.64 & 1349.98 \\
\hline 7 & XZ7 & 2387.52 & 0.65 & 1551.89 \\
\hline 8 & XZ8 & 2783.13 & 0.71 & 1976.02 \\
\hline 9 & XZ9 & 893.56 & 0.62 & 554.01 \\
\hline 10 & XZ10 & 1204.82 & 0.55 & 662.65 \\
\hline 11 & XZ11 & 879.24 & 0.58 & 509.96 \\
\hline 12 & $\mathrm{XZ12}$ & 2104.45 & 0.63 & 1325.80 \\
\hline 13 & XZ13 & 1452.52 & 0.72 & 1045.81 \\
\hline 14 & XZ14 & 1342.59 & 0.67 & 899.54 \\
\hline 15 & XZ15 & 873.14 & 0.66 & 576.27 \\
\hline 16 & XZ16 & 874.22 & 0.57 & 498.31 \\
\hline 17 & XZ17 & 689.73 & 0.82 & 565.58 \\
\hline 18 & XZ18 & 1342.16 & 0.34 & 456.33 \\
\hline 19 & XZ19 & 1235.19 & 0.43 & 531.13 \\
\hline 20 & XZ20 & 984.23 & 0.67 & 659.43 \\
\hline
\end{tabular}

3.4. Potential Correction of Rugao Rural Residential Land Consolidation considering Farmers' Willingness. A survey on farmers' willingness in rural residential land consolidation potential estimation was organized and implemented by Rugao City in 20 towns, a sample survey was conducted according to the contents of the questionnaire in Appendix 3 , and experts were gathered to determine the weight of each factor in the rural residential land consolidation potential estimation. The weight of each factor in the structure of farmers' willingness in the estimation of rural residential land consolidation potential was determined by experts. The results of weight determination are given in Table 8 .

On this basis, the rural residential land consolidation actual potential correction factor, $\eta_{Y}$, considering farmers' willingness was determined based on the results of the questionnaire survey in each town, combined with the weights determined in Table 8. Then, according to (6), the rural residential land consolidation actual potential considering farmers' willingness was calculated, and the results are shown in Table 9.

3.5. Rugao Rural Residential Land Consolidation Potential Final Results. According to (9), we calculated the final rural residential land consolidation potential of 20 towns in Rugao City, and the results are given in Table 10.

Accordingly, the relevant departments of the Rugao municipal government can reasonably arrange the relevant 
TABLE 10: Final calculation of rural residential land consolidation realistic potential of 20 towns in Rugao City.

\begin{tabular}{|c|c|c|c|c|c|}
\hline Serial no. & Town name & Theoretical consolidation potential $q$ & Actual potential $Q_{N-E}$ & Actual potential $Q_{Y}$ & Final potential $Q$ \\
\hline 1 & $\mathrm{XZ1}$ & 2435.75 & 1412.74 & 1510.17 & 1461.46 \\
\hline 2 & XZ2 & 2213.45 & 1483.01 & 1195.26 & 1339.14 \\
\hline 3 & $\mathrm{XZ3}$ & 1323.89 & 900.25 & 675.18 & 787.72 \\
\hline 4 & $\mathrm{XZ4}$ & 1876.34 & 1369.73 & 713.01 & 1041.37 \\
\hline 5 & XZ5 & 1984.23 & 952.43 & 1448.49 & 1200.46 \\
\hline 6 & XZ6 & 2109.35 & 1117.96 & 1349.98 & 1233.97 \\
\hline 7 & XZ7 & 2387.52 & 1146.01 & 1551.89 & 1348.95 \\
\hline 8 & XZ8 & 2783.13 & 1502.89 & 1976.02 & 1739.46 \\
\hline 9 & XZ9 & 893.56 & 491.46 & 554.01 & 522.74 \\
\hline 10 & XZ10 & 1204.82 & 759.04 & 662.65 & 710.85 \\
\hline 11 & XZ11 & 879.24 & 668.22 & 509.96 & 589.09 \\
\hline 12 & $\mathrm{XZ12}$ & 2104.45 & 1620.43 & 1325.80 & 1473.12 \\
\hline 13 & XZ13 & 1452.52 & 740.79 & 1045.81 & 893.30 \\
\hline 14 & $\mathrm{XZ14}$ & 1342.59 & 832.41 & 899.54 & 865.98 \\
\hline 15 & XZ15 & 873.14 & 392.91 & 576.27 & 484.59 \\
\hline 16 & XZ16 & 874.22 & 507.05 & 498.31 & 502.68 \\
\hline 17 & XZ17 & 689.73 & 558.68 & 565.58 & 562.13 \\
\hline 18 & XZ18 & 1342.16 & 979.78 & 456.33 & 718.06 \\
\hline 19 & XZ19 & 1235.19 & 827.58 & 531.13 & 679.36 \\
\hline 20 & XZ20 & 984.23 & 757.86 & 659.43 & 708.65 \\
\hline Total & & 30989.51 & 19021.23 & 18704.82 & 18863.08 \\
\hline
\end{tabular}

TABLE 11: Farmers' willingness questionnaire in rural residential land consolidation potential estimation.

\begin{tabular}{|c|c|c|c|c|c|c|c|c|c|c|c|}
\hline \multirow{2}{*}{$\begin{array}{l}\text { Serial } \\
\text { no. } \\
1\end{array}$} & Question & \multicolumn{10}{|c|}{$\begin{array}{l}\text { Degree }(1 \text { is the lowest } \\
\text { degree, } 10 \text { is the highest } \\
\text { degree, please tick the } \\
\text { corresponding number })\end{array}$} \\
\hline & How well you know the policies related to rural residential land consolidation & 1 & 23 & & & & 6 & 7 & & 9 & \\
\hline 1 & How well you understand the tasks of rural residential land consolidation & & 23 & 34 & & & & 7 & 8 & 9 & 10 \\
\hline 2 & How well you understand the current conflict between land supply and demand & & 23 & 34 & & & & 7 & 8 & 9 & 10 \\
\hline 3 & How much you can support the work of rural residential land consolidation at your age & 1 & 23 & & & & & 7 & 8 & 9 & 10 \\
\hline 4 & $\begin{array}{l}\text { How much your family members who are not working outside the home can support the work of } \\
\text { rural residential land consolidation }\end{array}$ & 1 & 23 & & & & & & 8 & 9 & \\
\hline 5 & How much your education level can support the work of rural residential land consolidation & 1 & 23 & & & & & 7 & 8 & 9 & \\
\hline 6 & How much you are dissatisfied with the size of your current home & & 23 & 3 & & & & 7 & 8 & 9 & 10 \\
\hline 7 & How much you are dissatisfied with the surrounding environment of your home & & 23 & 3 & & & & & 8 & & \\
\hline 8 & How much you are dissatisfied with the current status of your family's facilities & & 23 & 3 & & & & 7 & 8 & & 10 \\
\hline 9 & How much you are satisfied with the expected area of your house after consolidation & 1 & 23 & 3 & & & & 7 & 8 & , & \\
\hline 10 & How much you are satisfied with the expected family income after the arrangement & 1 & 23 & 3 & & & & 7 & 8 & & 10 \\
\hline 11 & How much you are satisfied with the expected housing allowance after consolidation & & 23 & 3 & & & & & 8 & & \\
\hline 12 & How much you are satisfied with the expected living conditions after consolidation & & 23 & 3 & & & & & 8 & & \\
\hline 13 & How much you are satisfied with the expected supporting facilities after consolidation & 1 & 23 & 34 & & & & & 8 & y & 10 \\
\hline
\end{tabular}

rural residential land consolidation work according to the final results of the calculated rural residential land consolidation potential to ensure that the urban and rural construction land can meet the requirements.

\section{Conclusion and Discussion}

4.1. Conclusion. Under the background of rural revitalization and based on the new requirements of standardizing rural land improvement work, this study organically combines rural residential land consolidation and the protection of farmers' land rights and interests and provides an estimation method of the consolidation potential of rural residential land considering farmers' willingness. The estimation method is based on calculation of the theoretical potential and then constructs a comprehensive correction index system in three dimensions, natural conditions, economic feasibility, and farmers' willingness, so as to get the realistic potential of rural residential land consolidation. The comprehensive correction index system includes the following (1) Correction index system: calculation of the realistic potential of rural residential land consolidation based on natural conditions and economic feasibility. It includes three indicators of natural conditions (namely, the 
aggregation degree of rural settlements, the average slope of rural settlements, and the topographic relief) and three indicators of economic feasibility (namely, the per-capita GDP, available fiscal revenue, and the percentage of the income of the primary industry). (2) Further optimization of the correction index system: considering farmers' willingness. Firstly based on PSR theory, the study systematically analyzed the structure of farmers' willingness in rural residential land consolidation. And then, the study designed a scientific and operational questionnaire for farmers' willingness in rural residential land consolidation potential estimation and proposed a systematic survey implementation and result analysis method. On this basis, the optimization system of rural residential land consolidation potential estimation method considering farmers' willingness was constructed.

The feasibility of the estimation method is verified by a case. And, the estimation method initiates new ideas for estimating land consolidation potential in residential areas and provides effective support for the planning and implementation of rural residential land consolidation in each local area.

4.2. Discussion. Although the thesis has made some valuable explorations in the calculation of the realistic potential of rural residential land consolidation based on natural conditions, economic feasibility, and farmers' willingness, some shortcomings still need to be improved owing to the limitation of the research level:

(1) The paper does not carry out research in theoretical studies and case studies on issues such as subsequent rural residential land consolidation time-series partitioning, so this requires further research in the future.

(2) The paper does not yet take into account the relevant social benefits in the context of rural residential land consolidation potential estimation, so future attempts are needed to quantify the social benefits and incorporate them into the rural residential land consolidation potential estimation system.

\section{Appendix}

\section{A. Farmers' Willingness Questionnaire in Rural Residential Land Consolidation Potential Estimation}

This questionnaire was designed to effectively investigate farmers' willingness in rural residential land consolidation potential estimation. The questionnaire consists of 13 questions on 13 factors of rural residential land consolidation potential estimation. Please check the corresponding numbers according to your own understanding (Table 11).

\section{Data Availability}

The data used to support the findings of this study are available from the corresponding author upon request.

\section{Conflicts of Interest}

The authors declare no conflicts of interest.

\section{Acknowledgments}

This research was funded by the National Natural Science Foundation of China (grant no. 71801130); the Jiangsu Social Science Foundation Project (grant no. 18GLD013); the Training Program for Outstanding Young Teachers in Colleges and Universities in Anhui Province (gxgnfx2021004); and the Anhui Social Science Innovation and Development Research Project (grant no. 2020CX092).

\section{References}

[1] J. Guo, S. Xiao, and M. Ou, "Realistic potential calculation of rural settlements consolidation based on willingness of participants," China Land Science, vol. 31, no. 10, pp. 86-94, 2017.

[2] F. Li and Y. Liu, "Satisfactional effect analysis of participatory management in rural residential land consolidation," Journal of Agrotechnical Economics, vol. 6, pp. 116-126, 2018.

[3] Y. Qu, G. Jiang, Y. Yang, Z. Qiuyueb, L. Yulingb, and M. Wenqiub, "Multi-scale analysis on spatial morphology differentiation and formation mechanism of rural residential land: a case study in Shandong Province, China," Habitat International, vol. 71, pp. 135-146, 2018.

[4] H. Li, W. Song, and Y. Zhang, "Review of data preparation for rural settlement evolution research," Resources Science, vol. 41, no. 4, pp. 689-700, 2019.

[5] R. Su and C. Wang, "Rural settlement spatial layout optimization using network center radiation guidance for Yanba Village in Chongqing," Resources Science, vol. 40, no. 5, pp. 958-966, 2018.

[6] R. Yang, Q. Xu, and H. Long, "Spatial distribution characteristics and optimized reconstruction analysis of China's rural settlements during the process of rapid urbanization," Journal of Rural Studies, vol. 47, pp. 413-424, 2016.

[7] Y. Qu, S. Wei, R. Shang, and J. Zheng, "Spatial morphology of rural settlements based on site and functional characteristics," Resources Science, vol. 41, no. 6, pp. 1035-1047, 2019.

[8] F. Xu, Z. Wang, H. Zhang, and J. Chai, "Application of random forest algorithm in suitability evaluation of rural residential land," Resources Science, vol. 40, no. 10, pp. 2085-2098, 2018.

[9] F. Zhang, J. Zhou, and B. Zhang, "Construction land consolidation potential analysis for rural settlements from aspects of land use structure and their functions," Journal of China Agricultural University, vol. 21, no. 5, pp. 155-160, 2016.

[10] Y. Liu, Y. Yang, Y. Li, and J. Li, "Conversion from rural settlements and arable land under rapid urbanization in Beijing during 1985-2010," Journal of Rural Studies, vol. 9, no. 51, pp. 141-150, 2017.

[11] C. Conrad, M. Rudloff, I. Abdullaev, M. Thiel, F. Löw, and J. P. A. Lamers, "Measuring rural settlement expansion in Uzbekistan using remote sensing to support spatial planning," Applied Geography, vol. 62, pp. 29-43, 2015.

[12] Y. Qu, G. Jiang, B. Zhang, and H. Li, "Spatial characteristics of rural residential land transition and its economic gradient differentiation," Acta Geographica Sinica, vol. 72, no. 10, pp. 1845-1858, 2017. 
[13] Y. Qu, G.-h. Jiang, Z. Li, Y. Tian, and S. Wei, "Understanding rural land use transition and regional consolidation implications in China," Land Use Policy, vol. 82, pp. 742-753, 2019.

[14] W. Ma, G. Jiang, D. Wang, W. Li, H. Guo, and Q. Zheng, "Rural settlements transition (RST) in a suburban area of metropolis: internal structure perspectives," The Science of the Total Environment, vol. 615, pp. 672-680, 2018.

[15] A. De Montis, A. Ledda, V. Serra, M. Noce, M. Barra, and S. De Montis, "A method for analysing and planning rural built-up landscapes: the case of Sardinia, Italy," Land Use Policy, vol. 62, pp. 113-131, 2017.

[16] T. Muilu and J. Rusanen, "Rural definitions and short-term dynamics in rural areas of Finland in 1989-97," Environment and Planning A Economy and Space, vol. 36, no. 8, pp. 1499-1516, 2004.

[17] G. Dong, E. Xu, and H. Zhang, "Comparative study on rural settlement of different rural development type in north China plain," Journal of China Agricultural Resources and Regional Planning, vol. 40, no. 11, pp. 1-8, 2019.

[18] H. Long, Y. Li, Y. Liu, M. Woods, and J. Zou, "Accelerated restructuring in rural China fueled by 'increasing vs. decreasing balance' land-use policy for dealing with hollowed villages," Land Use Policy, vol. 29, no. 1, pp. 11-22, 2012.

[19] J. Xi, X. Wang, Q. Kong, and N. Zhang, "Spatial morphology evolution of rural settlements induced by tourism," Journal of Geographical Sciences, vol. 25, no. 4, pp. 497-511, 2015.

[20] G. Dong, E. Xu, and H. Zhang, "Spatiotemporal variation of driving forces for settlement expansion in different types of counties," Sustainability, vol. 8, no. 1, 2016.

[21] R. Zhang, G. Jiang, M. Wang, and W. Ma, "Layout classification of rural settlement based on combination of multidimensional characteristics," Transactions of the Chinese Society of Agricultural Engineering, vol. 31, no. 4, pp. 286-292, 2015.

[22] G. Dong, E. Xu, and H. Zhang, "The spatial distribution and evolution of different types of rural settlements on HuangHuai-Hai Plain," Resources Science, vol. 39, no. 7, pp. 12481258, 2017.

[23] Y. Zou, C. Lv, Y. Zhou, and R. Yang, "Estimation of the consolidation potential of rural residential land based on planning regulation," Resources Science, vol. 38, no. 7, pp. 1266-1274, 2016.

[24] T.-t. Li, H.-l. Long, Y.-f. Wang, and S.-s. Tu, "The spatiotemporal characteristics and consolidation potential of rural housing land in farming area of the Huang-Huai-Hai Plain: the cases of five villages in Yucheng city," Journal of Natural Resources, vol. 35, no. 9, pp. 2241-2253, 2020.

[25] Y. He, Y. Chen, and Y. Yao, "Commentary on study methodology of rural residential land consolidation potential," Geography and Geo-Information Science, vol. 24, no. 4, pp. 80-83, 2008.

[26] Y. Wang, T. Zhai, and D. Yin, "Evaluation of land consolidation potential of vacant villages under background of rural revitalization -taking Wulian County of Shandong Province as an example," Bulletin of Soil and Water Conservation, vol. 39, no. 2, pp. 288-292, Article ID 300, 2019.

[27] H. Long, Y. Li, and Y. Liu, "Analysis of evolutive characteristics and their driving mechanism of hollowing villages in China," Acta Geographica Sinica, vol. 64, no. 10, pp. 12031213, 2009.

[28] K. Li, Y. Chen, and X. Yu, "Calculation of realistic potential and strategy of land consolidation in rural residential areas based on households' willingness," Journal of Natural Resources, vol. 28, no. 3, pp. 459-469, 2013. 